Drs. Teja Insyaf Sukariyadi, M.Pd
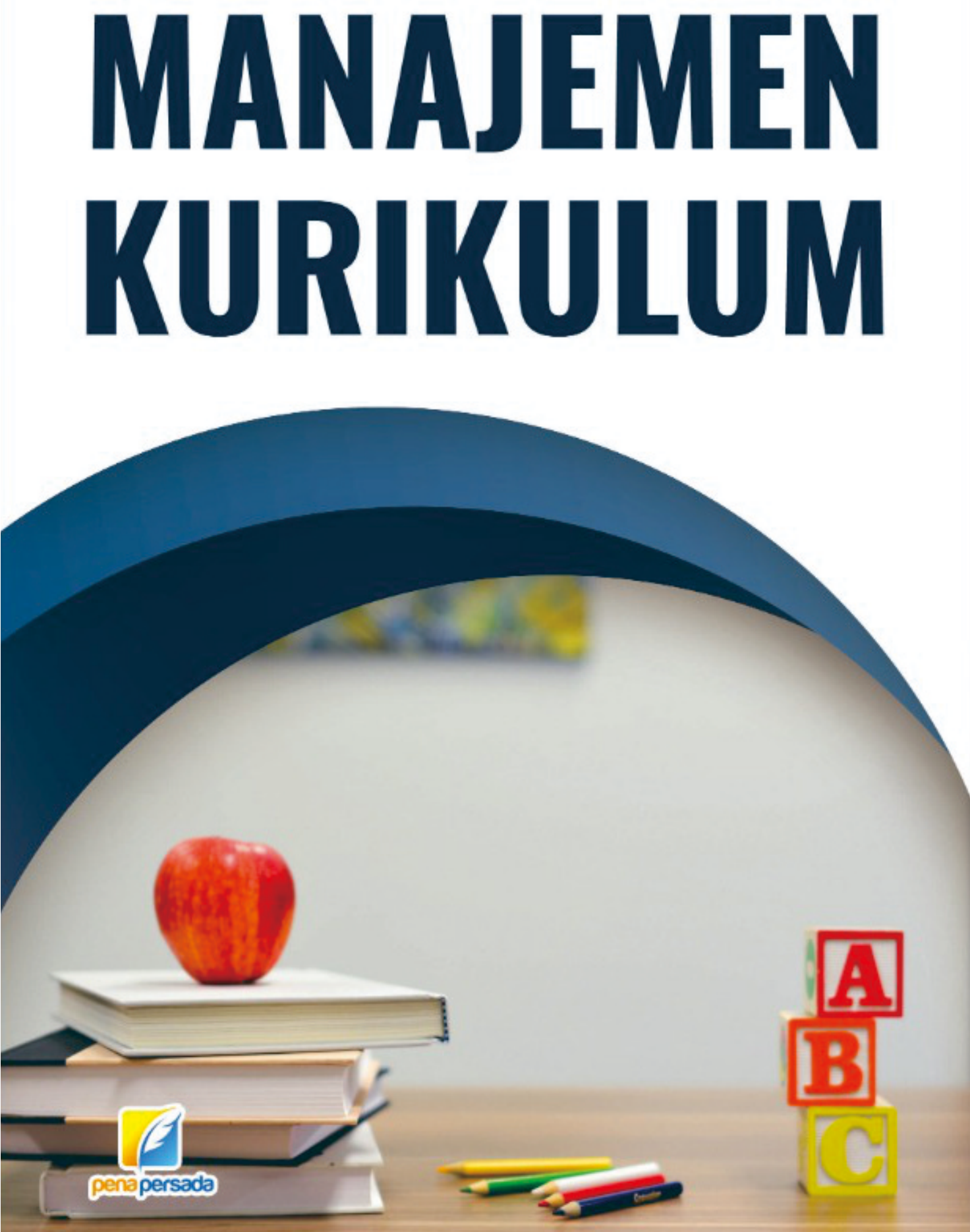


\section{MANAJEMEN KURIKULUM}

Drs. TEJA INSYAF SUKARIYADI, MPd.

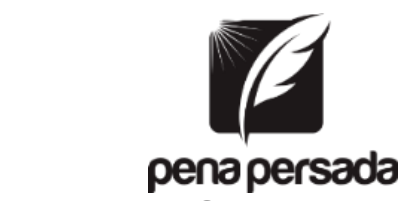

PENERBIT CV. PENA PERSADA 


\title{
MANAJEMEN KURIKULUM
}

Penulis:

Drs. Teja Insyaf Sukariyadi, MPd.

\author{
ISBN : 978-623-315-994-4 \\ Design Cover : \\ Retnani Nur Briliant \\ Layout : \\ Nofendy Ardyanto
}

\section{Penerbit CV. Pena Persada \\ Redaksi :}

Jl. Gerilya No. 292 Purwokerto Selatan, Kab. Banyumas Jawa Tengah

Email : penerbit.penapersada@gmail.com Website : penapersada.com Phone : (0281) 7771388

Anggota IKAPI

All right reserved

Cetakan pertama : 2022

Hak Cipta dilindungi oleh undang-undang. Dilarang memperbanyak karya tulis ini dalam bentuk apapun tanpa izin penerbit 


\section{KATA PENGANTAR}

Puji syukur alhamdulillah ke hadirat Allah SWT yang telah memberikan kekuatan dan hidayah-Nya sehingga buku Manajemen Kurikulum ini dapat terselesaikan.

Buku ini disusun untuk membantu pembaca, khususnya para guru, mahasiswa LPTK, calon guru dan pegiat pengembang kurikulum dalam usaha memahami perkembangan dan implementasi manajemen kurikulum di Indonesia.

Penulis menyadari buku ini meskipun sudah ditulis dengan cermat, tidak menutup kemungkinan masih adanya kekurangan mengingat keterbatasan kemampuan penulis. Untuk itu, saran dan kritik yang konstruktif dari pembaca senantiasa diharapkan demi sempurnanya buku ini. Semoga buku ini bermanfaat bagi kita semua.

Madiun, Januari 2022

Penyusun,

Drs. Teja Insyaf Sukariyadi, M.Pd. 


\section{DAFTAR ISI}

KATA PENGANTAR …................................................................. ii

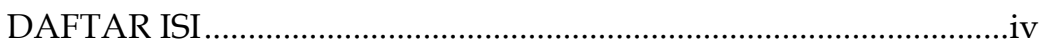

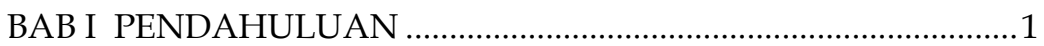

A. Konsep Kurikulum ................................................................

B. Arti Kata Kurikulum...............................................................

C. Pengertian Kurikulum Menurut Para Ahli ............................ 3

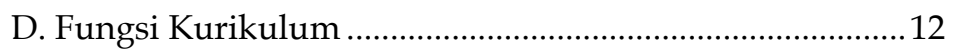

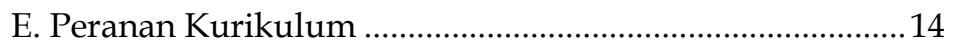

F. Komponen Kurikulum ........................................................ 17

G. Landasan Pengembangan Kurikulum ..................................18

H. Model Pengembangan Kurikulum .......................................20

I. Prinsip Pengembangan Kurikulum ......................................24

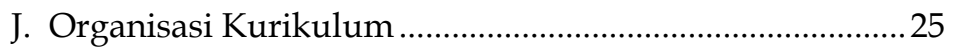

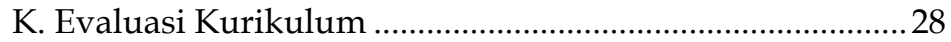

L. Manajemen Kurikulum .......................................................... 31

M. Pengertian Manajemen Kurikulum........................................32

BAB II KONSEP MANAJEMEN KURIKULUM................................34

A. Ruang Lingkup Manajemen Kurikulum ............................. 35

B. Prinsip Manajemen Kurikulum................................................ 36

C. Fungsi Manajemen Kurikulum ............................................... 41

D. Karateristik Manajemen Kurikulum ................................... 42

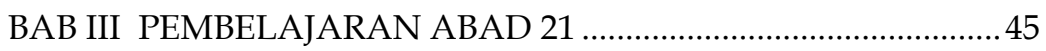

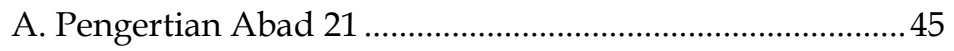

B. Tujuan Pendidikan Nasional Abad 21 .................................. 46

C. Paradigma Pendidikan Nasional Abad 21 .......................... 48

D. Empat Prinsip Pokok Pembelajaran Abad Ke-21 .............. 62 
E. Antisipasi Yang Perlu Dilakukan Dalam Pendidikan

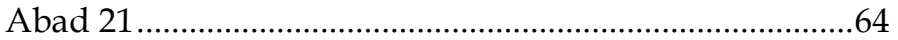

F. Tuntutan Pendidikan Pada Abad 21 ....................................67

BAB IV POSISI MANAJEMEN KURIKULUM DALAM

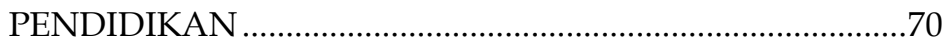

A. Pendahuluan.......................................................................

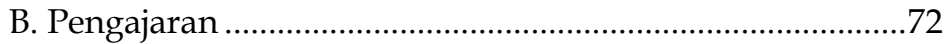

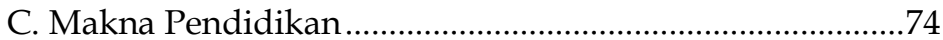

D. Hubungan Kurikulum Dan Pengajaran ..............................77

E. Posisi Manajemen Kurikulum Dalam Pendidikan ...........82

BAB V MODEL-MODEL MANAJEMEN KURIKULUM .................89

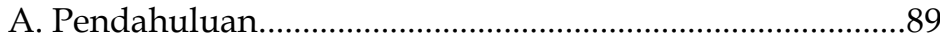

B. Model Kurikulum Tahun 1947 ...............................................90

C. Model Kurikulum Tahun 1952 _...........................................92

D. MODEL KURIKULUM TAHUN 1964 …...........................96

E. Model Kurikulum Tahun 1968 .............................................97

F. Model Kurikulum Tahun 1975.............................................99

G. Model Kurikulum Tamun 1984.........................................100

H. Model Kurikulum Tahun 1994 ...........................................104

I. Model Kurikulum Tahun 2004 .........................................107

J. Model Kurikulum Tahun 2006 .........................................109

K. Model Manajemen Kurikulum Tahun 2013 .....................111

L. Model-Model Konsep Kurikulum........................................114

BAB VI MODEL-MODEL MANAJEMEN PEMBELAJARAN.....120

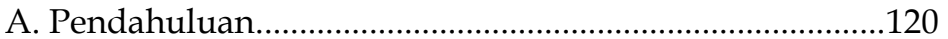

B. Model-Model Pembelajaran.................................................121 
BAB VII KEPEMIMPINAN DALAM MANAJEMEN

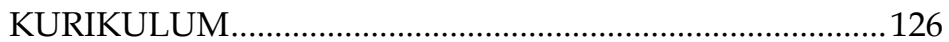

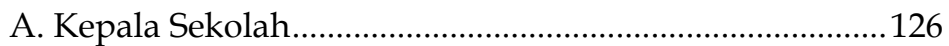

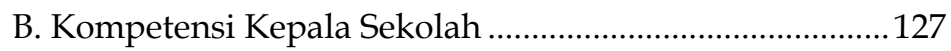

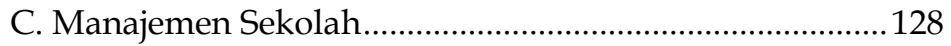

D. Hubungan Manajemen Kepala Sekolah Dengan Manajemen Kurikulum ......................................................130

BAB VIII MANAJEMEN PELAKSANAAN KURIKULUM DI

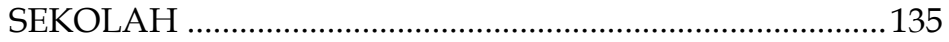

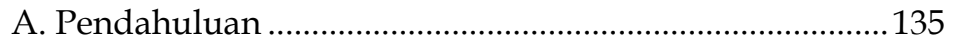

B. Peran Guru Dalam Pengembangan Kurikulum ..............136

C. Kemampuan Guru Dalam Implementasi Kurikulum ..137

D. Faktor-Faktor Yang Memengaruhi Implementasi

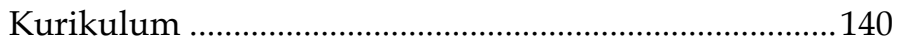

E. Prinsip-Prinsip Implementasi Kurikulum .........................141

F. Tahap-Tahap Implementasi Kurikulum ...........................142

BAB IX MANAJEMEN PEMBELAJARAN …………………..........146

A. Pengertian Manajemen Pembelajaran .................................146

B. Tahap-Tahap Manajemen Pembelajaran.............................147

C. Pelaksanaan Manajemen Pembelajaran..............................158

D. Pelaksanaan Kegiatan Pembelajaran ..................................159

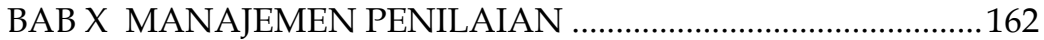

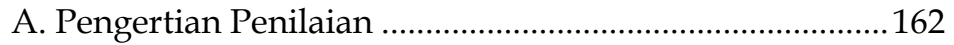

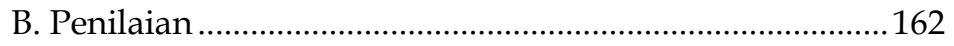

C. Konsep Dasar Penilaian Pendidikan....................................163

D. Tujuan Penilaian Pendidikan..............................................164

E. Sasaran Penilaian Pendidikan ...........................................166 
F. Fungsi Penilaian.................................................................168

G. Prinsip Penilaian Pendidikan ............................................170

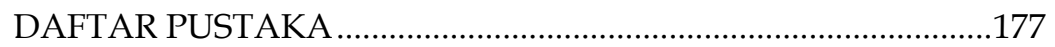




\section{MANAJEMEN KURIKULUM}




\section{BAB I \\ PENDAHULUAN}

\section{A. Konsep Kurikulum}

Kurikulum adalah salah satuh komponen yang memegang peranan penting dalam sistem pendidikan. Kurikulum akan memberikan arah dan menjadi pedoman dalam pelaksanaan proses pendidikan dan pengajaran di sebuah institusi, khususnya di lembaga-lembaga pendidikan formal. Tanpa kurikulum proses pendidikan tidak akan berjalan terarah dengan baik. Bahkan secara ekstrim bisa dikatakan, jika tidak ada kurikulum maka sekolah tidak akan ada proses pendidikan dan pengajaran. Hal itu karena yang menentukan aktivitas proses pendidikan berupa kegiatan pembelajaran semuanya ditentukan dalam kurikulum.

Berpijak dari kenyataan tersebut, maka tidak berlebihan jika Beauchamp (1998) menyebutkan bahwa, "curriculum is the heart education". Kurikulum adalah jantungnya pendidikan.

\section{B. Arti Kata Kurikulum}

Kurikulum (curriculum), yang pada awalnya digunakan dalam dunia olahraga, berasal dari kata curir (pelari) dan curere (tempat berpacu). Pada saat itu kurikulum diartikan sebagai jarak yang harus ditempuh oleh seorang pelari mulai dari start sampai finish untuk memperoleh medali/penghargaan.

Pada saat awal kata tersebut muncul, kurikulum diartikan sebagai jarak yang harus ditempuh oleh seorang pelari mulai dari start sampai finish untuk memperoleh medali/penghargaan. Pada zaman Romawi kuno kurikulum adalah kata yang digunakan untuk lintasan pacu kereta.

Di Indonesia istilah kurikulum boleh dikatakan baru menjadi popular sejak tahun lima puluhan. yang dipopulerkan oleh orang-orang yang memperoleh pendidikan di Amerika Serikat. 
Dalam perkembangannya, pengertian tersebut kemudian diterapkan dalam dunia pendidikan menjadi sejumlah mata pelajaran (subject) yang harus ditempuh oleh seorang siswa dari awal sampai akhir program pelajaran untuk memperoleh penghargaan dalam bentuk ijazah.

Dari pengertian tersebut, dalam kurikulum terkandung dua hal pokok, yaitu : (1) adanya mata pelajaran yang harus ditempuh oleh siswa, dan (2) adanya tujuan utamanya yaitu untuk memperoleh ijazah.

Dengan demikian, implikasi terhadap praktik pengajaran yaitu setiap siswa harus menguasai seluruh mata pelajaran yang diberikan dan menempatkan guru dalam posisi yang sangat penting dan menentukan. Keberhasilan siswa ditentukan oleh seberapa jauh mata pelajaran tersebut dikuasainya dan biasanya disimbolkan dengan skor yang diperoleh setelah mengikuti suatu tes atau ujian.

Pengertian kurikulum seperti disebutkan di atas dianggap pengertian yang sempit atau sangat sederhana. Jika kita mempelajari buku-buku atau literatur lainnya tentang kurikulum, terutama yang berkembang di negara-negara maju, maka akan ditemukan banyak pengertian yang lebih luas dan beragam. Kurikulum itu tidak terbatas hanya pada sejumlah mata pelajaran saja, tetapi mencakup semua pengalaman belajar (learning experiences) yang dialami siswa dan mempengaruhi perkembangan pribadinya.

Bahkan Harold B. Alberty (1965) memandang kurikulum sebagai semua kegiatan yang diberikan kepada siswa di bawah tanggung jawab sekolah (all of the activities that are provided for the students by the school). Kurikulum tidak dibatasi pada kegiatan di dalam kelas saja, tetapi mencakup juga kegiatankegiatan yang dilakukan oleh siswa di luar kelas.

Pendapat yang senada dan menguatkan pengertian tersebut dikemukakan oleh Saylor, Alexander, dan Lewis (1974) yang menganggap kurikulum sebagai segala upaya sekolah untuk mempengaruhi siswa supaya belajar, baik dalam ruangan kelas, di halaman sekolah, maupun di luar sekolah 
Menurut Suyanto (2007) kurikulum adalah sebagai aktifitas yang menyangkut semua kegiatan yang dilakukan dan dialami peserta didik dalam perkembangan baik formal maupun informal guna mencapai tujuan.

Sedangkan dalam konteks pendidikan islam (Tarbiyah Al-lslamiyah) istilah kurikulum sama dengan Manhaj atau Nahju yang definisinya adalah jalan atau cara yang dilakukan seseorang agar dengan segera mencapai tujuan hidup (Qurah,1979 :237).

Kurikulum menunjukkan semua pengalaman belajar siswa di sekolah. Atas dasar pandangan tersebut, diperoleh kesan bahwa sekolah dapat dipandang sebagai miniatur masyarakat, karena di dalam lingkungan sekolah murid mempelajari segi-segi kehidupan sosial, seperti norma-norma, nilai-nilai, adat istiadat, gotong-royong atau kerja sama, dan sebagainya. Semua ini mirip dengan apa yang terjadi di lingkungan masyarakat. Dengan demikian, proses pendidikan dapat diarahkan kepada pembentukan pribadi anak secara utuh, dan ini dicapai melalui kurikulum sekolah.

\section{Pengertian Kurikulum Menurut Para Ahli}

Kurikulum telah banyak dibahas dan diartikan oleh banyak ahli. Tentu saja pendapat para ahli tersebut sedikit banyak tidak terlepas dari disiplin ilmu atau pengalaman yang mereka dapatkan.

Adapun beberapa pengertian kurikulum menurut para ahli, adalah sebagai berikut :

1. Harold B. Alberty (1965) memandang kurikulum sebagai semua kegiatan yang diberikan kepada siswa di bawah tanggung jawab sekolah (all of the activities that are provided for the students by the school). Kurikulum tidak dibatasi pada kegiatan di dalam kelas saja, tetapi mencakup juga kegiatankegiatan yang dilakukan oleh siswa di luar kelas.

2. Saylor, Alexander, dan Lewis (1974) yang menganggap kurikulum sebagai segala upaya yang dilakukan sekolah 
untuk mestimuli siswa agar belajar, baik dalam ruangan kelas, di halaman sekolah, maupun di luar sekolah.

3. John l.Goddlad (1963) A curriculum consists of all those learnings intended for a student or group of students.

(Kurikulum terdiri dari semua pembelajaran yang ditujukan untuk siswa atau sekelompok siswa)

4. L. Thomas Hopkins (1941) The curriculum (is a design made) by all of those who are most intimately concerned with the activities of the life of the children while they are in school...... curriculum must be as flexible as life and living. It cannot be made beforehand and given to pupils and teachers to install. (Also, it).. represents those learning each child selects, accepts, and incorporates into himself to act with, in, and upon in subsequent experiences.

(Kurikulum (adalah desain yang dibuat) oleh semua orang yang paling dekat dengan aktivitas kehidupan anak-anak selama mereka di sekolah.....kurikulum harus sefleksibel kehidupan dan kehidupan. Itu tidak bisa dibuat sebelumnya dan diberikan kepada murid dan guru untuk dipasang. (Juga, itu)...mewakili pembelajaran yang dipilih, diterima, dan dimasukkan oleh setiap anak ke dalam dirinya sendiri untuk bertindak dengan, dalam, dan atas dalam pengalaman berikutnya)

5. H. H. Giles, S. P. McCutchen, and A. N. Zechiel (1942) ... the curriculum is. . the total experiences with which the school deals in educating young people

(kurikulum adalah... pengalaman total yang berhubungan dengan sekolah dalam mendidik kaum muda)

6. Peter F. Oliva (1 997: 12), “...curriculum it self is a construct or concept, a verbalization of an extremely complex idea or set of ideas".

(“...kurikulum itu sendiri adalah sebuah konstruk atau konsep, sebuah verbalisasi dari ide atau rangkaian ide yang sangat kompleks".)

7. Burnett J. Galen Saylor and William M, Alexander (1966 and 1974) ...(the curriculum is)... all learning opportunities provided by the school... a plan for providing sets of learning opportunities 
to achieve broad educational goals and related specific objectives for an identifiable population served by a single school centre. (...(kurikulum adalah)...semua kesempatan belajar yang disediakan oleh sekolah...sebuah rencana untuk menyediakan serangkaian kesempatan belajar untuk mencapai tujuan pendidikan yang luas dan tujuan khusus terkait untuk populasi yang dapat diidentifikasi yang dilayani oleh satu pusat sekolah)

8. Hilda Taba (1962), “...A curriculum is a plan for learning; therefore, what is known about the learning process and the development of the individual has bearing on the shaping of curriculum"

Kurikulunł adalah rencana pembelajaran; oleh karena itu. apa yang diketahui tentang proses belajar dan perkembangan individu berpengaruh pada pembentukan kurikulum")

Pengertian kurikulum senantiasa berkembang terus sejalan dengan perkembangan teori dan praktik pendidikan. Dengan beragamnya pendapat mengenai pengertian kurikulum, maka secara teoretis kita agak sulit menentukan satu pengertian vang dapat merangkum semua pendapat. Berdasarkan hasil kajian, diperoleh beberapa dimensi pengertian kurikulum. R. Ibrahim (2005) mengelompokkan kurikulum menjadi tiga dimensi, yaitu kurikulum sebagi substansi, kurikulum sebagi sistem, dan kurikulum sebagai bidang studi. Dimensi pertama memandang kurikulum sebagai rencana kegiatan belajar bagi siswa di sekolah atau sebagai perangkat tujuan yang ingin dicapai.

Suatu kurikulum dapat juga menunjuk pada suatu dokumen yang berisi rumusan tentang tujuan, bahan ajar, kegiatan belajar mengajar, jadwal dan evaluasi. Suatu kurikulum juga dapat digambarkan sebagi dokumen tertulis sebagi hasil persetujuan bersama antara penyusun kurikulum dan pemegang kebijakan pendidikan dan masyarakat. Dimensi kedua memandang kurikulum sebagai bagian dari sistem 
persekolahan, sistem pendidikan dan bahkan sistem masyarakat. Suatu sistem kurikulum mencakup stuktur personalia dan prosedur kerja bagaimana cara menyusun kurikulum, melaksanakan, mengevaluasi dan menyempurnakannya.

Hasil dari suatu sistem adalah tersusunnya suatu kurikulum dan fungsi dari sistem kurikulum adalah memelihara kurikulum agar tetap dinamis. Dimensi ketiga memandang kurikulum sebagai bidang studi yaitu bidang studi kurikulum. Hal ini merupakan kajian para ahli kurikulum dan ahli pendidikan dan pengajaran.

Mereka yang mendalami bidang kurikulum mempelajari konsep-konsep dasar tentang kurikulum, melalui studi kepustakaan dan berbagai kegiatan penelitian dan percobaan. mereka menemukan hal-hal baru yang dapat memperkaya dan memperkuat bidang studi kurikulum.

Nana Syaodih Sukmadinata (2005) mengemukakan pengertian kurikulum ditinjau dari liga dimensi, yaitu sebagai ilmu, sebagai sistem dan sebagai rencana. Kurikulum sebagi ilmu dikaji konsep, asumsi, teori-teori dan prinsip-prinsip dasar tentang kurikulum. Kurikulum sebagai sistem dijelaskan kedudukan kurikulum dalam hubungannya dengan sistemsistem lain, komponen-komponen kurikulum, kurikulum dalam berbagai jalur, jenjang, jenis pendidikan, manajemen kurikulum,dan sebagainya. Kurikulum sebagai rencana diungkap beragam rencana dan rancangan atau desain kurikulum. Rencana bersifat menyeluruh untuk semua jalur, jenjang dan jenis pendidikan atau khusus untuk jalur, jenjang dan jenis pendidikan tertentu. Demikian pula dengan rancangan atau desain, terdapat desain berdasarkan konsep, tujuan, isi, proses, masalah, kebutuhan siswa.

S. Hamid Hasan (1988) mengemukakan bahwa pada saat sekarang istilah kurikulum memiliki empat dimensi pengertian, di mana satu dimensi dengan dimensi lainnya saling berhubungan. Keempat dimensi kurikulum tersebut yaitu: 
1. Kurikulum sebagai suatu ide/gagasan

2. Kurikulum sebagai suatu rencana tertulis yang sebenarnya merupakan perwujudan dari kurikulum sebagai suatu ide,

3. Kurikulum sebagai suatu kegiatan yang sering pula disebut dengan istilah kurikulum sebagai suatu realita atau implementasi kurikulum. Secara teoretis dimensi kurikulum ini adalah pelaksanaan dari kurikulum sebagai suatu rencana tertulis.

4. Kurikulum sebagai suatu hasil yang merupakan konsekuensi dari kurikulum sebagai suatu kegiatan.

Selanjutnya bila kita merujuk pada dimensi pengertian yang terakhir, maka dapat dengan mudah mengungkap keempat dimensi kurikulum tersebut dikaitkan dengan pengertian kurikulum.

1. Pengertian kurikulum dihubungkan dengan dimensi ide

Pengertian kurikulum sebagai dimensi yang berkaitan dengan ide pada dasarnya mengandung makna bahwa kurikulum itu adalah sekumpulan ide yang akan dijadikan pedoman dalam pengembangan kurikulum selanj utnya. Pengertian-pengertian kurikulum yang berkaitan dengan dimensi ini, di antaranya:

a. "the content of instruction withoul rejerence to instructional ways or means" (flemy C. Morrison, 1940). isi instruksi tanpa mengacu pada cara atau sarana instruksional")

b. ".... curriculum is the substance of the school program. It is the content pupils are expected to learn" (Donald E. Orlosky and B. Othanel Smith, 1978).

(“....kurikulum adalah substansi program sekolah. Ini adalah konten yang diharapkan dipelajari oleh siswa") "...curriculum it self is a construct or concept, a verbalization ofan extremely complex idea or set of ideas" (Oliva, 1997:12).

c. ("...kurikulum itu sendiri adalah sebuah konstruk atau konsep, verbalisasi dari ide yang sangat kompleks atau serangkaian ide) 
2. Pengertian kurikulum dikaitkan dengan dimensi rencana

Maka dari dimensi kurikulum ini adalah sebagai seperangkat rencana dan cara mengadmistrasikan tujuan, isi, dan bahan pelajaran serta cara yang digunakan sebagai pedoman penyelenggaraan kegiatan pembelajaran untuk mencapai tujuan Pendidikan tertentu. Pengertian-pengertian kurikulum yang berkaitan dengan dimensi ini, di antaranya:

a. "....A curriculutn is a plan learning; therefore, what is known about the learning process and the developtment of the individual has bearing on the shaping curriculum" (Hilda Taba, 1962).

(.....Kurikulum adalah rencana pembelajaran; Oleh karena itu, apa yang diketahui tentang proses belajar dan perkembangan individu berpengaruh pada pembentukan kurikulum)

b. "......all planned learning outcomes for which the school is responsible" (W Popham and Eva L. Baker, 1970). (“....semua hasil pembelajaran yang direncanakan yang menjadi tanggungjawab sekolah")

"....the planned and guided learning experiences and intended learning outcomes, formulated through the systematic reconstruction of knowledge and experiences of the school, for learner's continuous and will full growth in personal-social competence" (Daniel Tanner and Laurel Tanner, 1975).

(“....pengalaman belajar yang direncanakan dan dipandu dan hasil belajar yang dimaksudkan, dirumuskan melalui rekonstruksi sistematis pengetahuan dan pengalaman sekolah, untuk pertumbuhan siswa yang berkelanjutan dan penuh dalam kompetensi pribadi sosial)

3. Pengertian kurikulum dikaitkan dengan dimensi aktifitas

Pengertian kurikulum sebagai dimensi aktifitas memandang kurikulum merupakan segala aktifitas dari guru dan siswa dalam proses Pembelajaran di sekolah. Pengertian-pengertian kurikulum yang berkaitan dengan dimensi ini, di antaranya: 
a. . . The curriculum [is a design, made] by all of those who are most intimately concerned with [he activities of the life of the children while they are in school... a curriculum must be as flexible as life and living. It cannot be made beforehand and given to pupils and teachers to install.[also it/.. represents those learning each child selects, accepts, and incorporates into himself to act with, in, and upon in subsequent experiences" (L. Thomas Hopkins, 1941).

(“.....Kurikulum [adalah desain, dibuat] oleh semua orang yang paling dekat dengan aktivitas kehidupan anak-anak selama mereka di sekolah... kurikulum harus sefleksibel kehidupan dan hidup. Itu tidak dapat dibuat sebelumnya dan diberikan kepada murid dan guru untuk dipasang.[juga itu/.. mewakili pembelajaran yang dipilih, diterima, dan dimasukkan oleh setiap anak ke dalam dirinya sendiri untuk bertindak dengan, dalam, dan atas dalam pengalaman berikutnya")

b. "[the curriculum is] the...stream of guided activities that constitutes the life of young people and their elders. [in a much earlier book, Rugg disapprovingly spoke of the traditional curriculum as one...... passing on description of earlier cultures and to perpetuating dead languages' and abstract techniques which were usefill to no more than a negligible fraction of our population" (Harold Rugg, 1947).

("kurikulum adalah aliran kegiatan terpandu yang membentuk kehidupan orano muda dan orang tua mereka. [dalam buku yang jauh lebih awal, Rugg tidak setuju berbicara tentang kurikulum tradisional sebagai satu meneruskan deskripsi budaya sebelumnya dan untuk melestarikan bahasa mati dan teknik abstrak yang berguna tidak lebih dari sebagian kecil dari populasi kita")

c. "All of the activities that are providecl for students by the school constituttes its curriculum" (Harold Alberty, 1953). (“Semua kegiatan yang disediakan untuk siswa oleh sekolah merupakan kurikulumnya") 
4. Pengertian kurikulum dikaitkan dengan dimensi hasil

Definisi kurikulum sebagai dimensi hasil memandang kurikulum itu sangat memperhatikan hasil yang akan dicapai oleh siswa agar sesuai dengan apa yang telah direncanakan dan yang menjadi tujuan dari kurikulum tersebut.

Pengertian-pengertian kurikulum yang berkaitan dengan dimensi ini, di antaranya:

a. "....a structured series of intended learning outcomes “(Mauritz Johnson, Jr., 1967).

(“....serangkaian terstruktur dari hasil pembelajaran yang diinginkan)

b. "Curriculum is defined as a plan for achieving intended learning outcomes: a plan concerned with purposes, with what is 10 be learned and with the result of instruction" (Unruh and Unruh, 1984:96).

("Kurikulum didefinisikan sebagai rencana untuk mencapai hasil belajar yang dimaksudkan: rencana yang berkaitan dengan tujuan, dengan apa yang akan dipelajari dan dengan hasil instruksi")

c. "segala usaha yang dilakukan oleh sekolah untuk memperoleh hasil yang diharapkan dalam situasi di dalam ataupun di luar sekolah " (Hilda Taba dalam Nasution, Azas-azas kurikulum).

Pandangan atau anggapan yang sampai saat ini masih lazim dipakai dalam dunia pendidikan dan persekolahan di negara kita, yaitu kurikulum sebagai suatu rencana tertulis yang disusun guna memperlancar proses pembelajaran. Hal ini sesuai dengan rumusan pengertian kurikulum seperti yang tertera dalam Undang-undang No. 20 Tahun 2003 tentang Sistem Pendidikan Nasional bahwa "kurikulum adalah seperangkat rencana dan pengaturan mengenai tujuan, isi dan bahan pelajaran serta cara yang digunakan sebagai pedoman penyelenggaraan kegiatan pembelajaran untuk mencapai tujuan pendidikan tertentu". 
Kurikulum juga sering dibedakan antara kurikulum sebagai rencana (curriculum plan) dengan kurikulum yang fungsional (functioning curricullum). Menurut Beauchamp "A curriculum is a written document which may contain many ingredients, but basically it is a plan for the education of pupils during their enrollment in given school"

Beauchamp lebih memberikan tekanan bahwa kurikulum adalah suatu rencana pendidikan atau pengajaran. Pelaksanaan rencana itu sudah masuk pengajaran. Selanjutnya, Zais menjelaskan bahwa kebaikan suatu kurikulum tidak dapat dinilai dari dokumen tertulisnya saja, melainkan harus dinilai dalam proses pelaksanaan fungsinya di dalam kelas. Kurikulum bukan hanya merupakan rencana tertulis bagi pengajaran, melainkan sesuatu yang fungsional yang beroperasi dalam kelas, yang memberi pedoman dan mengatur lingkungan dan kegiatan yang berlangsung di dalam kelas. Rencana tertulis merupakan dokumen kurikulum (curriculum document or, inert curriculum), sedangkan kurikulum yang dioperasikan di kelas merupakan kurikulum fungsional (functioning, live or operative curriculum)

Dimensi kurikulum sebagai mata pelajaran sangat erat kaitannya dengan usaha untuk mendapatkan ijazah. Ijazah sendiri pada dasarnya menggambarkan kemampuan. Artinya, apabila seorang siswa telah mendapatkan ijazah berarti siswa tersebut dapat dikatakan telah menguasai mata pelajaran sesuai dengan kurikulum yang berlaku.

Dimensi kurikulum sebagai pengalaman belajar merupakan seluruh kegiatan yang dilakukan oleh siswa baik di dalam maupun di luar sekolah asalkan kegiatan tersebut berada di bawah tanggung jawab guru (sekolah). Kegiatan-kegiatan tersebut tidak hanya terbatas pada kegiatan intra maupun kegiatan ekstrakurikuler tetapi kegiatan apa saja yang dilakukan oleh siswa selama berada di bawah tanggung jawab guru (sekolah) adalah kurikulum. 